\title{
O SINDICALISMO ITALIANO ENTRE CRISE DE REPRESENTATIVIDADE E MUDANÇAS DAS RELAÇÕES INDUSTRIAIS
}

\author{
Davide Bubbico ${ }^{\mathrm{a}}$ \\ aé pesquisador em Sociologia Econômica e do Trabalho pelo Departamento de Ciências \\ Econômicas e Estatísticas da Universidade de Salerno. Salerno, Itália. \\ E-mail:<dbubbico@unisa.it> \\ Orcid: 0000-0003-0981-0651 \\ http://dx.doi.org/10.1590/0102-287315/104
}

\section{Introdução}

O sindicato italiano representa, no contexto europeu, uma experiência específica fortemente afetada pela história recente do país, sobretudo quando no período fascista todas as estruturas associativas, como o sindicato, foram incluídas na construção do estado corporativo (Frank, 1990). A reconstrução da presença sindical nas fábricas aconteceu já em 1943, antes do fim da guerra, nas áreas libertadas ou clandestinamente naquelas ainda ocupadas, com a reconstituição das "comissões internas" que tinham sido abolidas pelo fascismo em 1925 e que permaneceram vivas depois da guerra até 1970 - ano em que foram substituídas pelos "conselhos de fábrica" (Turone, 1981)․․

\footnotetext{
1 Nas comissões internas podiam candidatar-se inclusive trabalhadores independentes, que não pertenciam a nenhuma organização sindical. Por isso - também mais próximos à empresa - eram frequentemente considerados "entidades-expressão" das empresas. Ademais, as comissões internas tinham poder contratual limitado sobre as condições de trabalho; em muitos casos, se circunscreviam apenas ao controle da aplicação dos contratos. Quando no início de 1970 foram substituídos pelos Conselhos de fábrica com a eleição dos delegados por departamento, não se tratava mais de um organismo com poderes genéricos, mas capazes de intervir
} 
De outro lado, a experiência mais recente do sindicato italiano é parte do protagonismo do movimento operário europeu que tem contribuído de forma relevante na construção do Estado de bem-estar em vários países do continente, mesmo que ainda hoje - apesar da existência da União Europeia - existam diferenças importantes entres os sindicatos europeus. Não há um "sindicato europeu", mas apenas uma Confederação Europeia dos Sindicatos (CES) é assim a diferença na organização, nos níveis de representação e nas taxas de sindicalização entre os países da União, mais do que nunca, em tempos recentes, com a entrada dos países do antigo bloco soviético, em que organizações sindicais aparecem cada vez mais fracas e fortemente influenciadas pelo poder empresarial (Congiu, 2004; Magda, 2017). Essas diferenças emergem em particular entre a experiência dos países do Norte da Europa e os do Centro e Sul: de um lado, o sindicato dos países escandinavos - Dinamarca, Alemanha ou Holanda -, onde o sindicato único por categoria é mais difundido e o caráter organizacional é mais forte; e, de outro, os países do Sul da Europa - incluída Itália, França, Espanha e Bélgica -, onde a formação de um sindicato numa base ideológica tem sido tradicionalmente mais forte juntamente com a dimensão do pluralismo sindical. Um caso específico é o da Inglaterra (Bernaciak, GumbrellMcCormick e Hyman, 2014; Del Rossi, 2012)².

muito mais sobre os problemas do quotidiano da fábrica. Além disso, a experiência do conselho de fábrica predispõe que sejam eleitos delegados por área de trabalho homogênea (ou seja, por cada departamento) e não mais simplesmente em representação da inteira fábrica passagem às RSU que aconteceu no início dos anos 90 , aos representantes empresariais são garantidas mais explicitamente, atribuições de contratação, mas sobretudo as três principais confederações se reservam a nomeação de um terço das RSU (Rappresentanze Sindacali Unitarie) em virtude de maior representatividade, condição que se tornou menor nos últimos anos, sendo os dois terços restantes eleitos pelos trabalhadores.

${ }^{2}$ A experiência sindical na Inglaterra caracteriza-se desde sempre por ser mais corporativa, peculiar às trade unions e pela estreita relação entre sindicato e o Partido Trabalhista. O caráter de sindicato das profissões, mais que dos trabalhadores, é um dos aspectos que identifica, desde as origens, o sindicato inglês. Com relação 
O pluralismo é uma das principais características do sistema sindical italiano, pois dá a importância, nas relações sindicais, do papel das três grandes confederações: CGIL (Confederazione Generale Italiana del Lavoro), CISL (Confederazione Italiana Sindacati Lavoratori) e UIL (Unione Italiana del Lavoro). O sindicato está organizado em grandes categorias por sector económico e conta também com uma presença generalizada em nível territorial (câmaras de trabalho, ofícios territoriais, ofícios fiscais pela declaração de renda etc.). Contrariamente ao padrão brasileiro, a contratação coletiva nacional de categoria profissional é a marca dominante da negociação sindical italiana, embora nos últimos anos as tentativas de superação dos Contratos Coletivos Nacionais de Trabalho (Contratti Collettivi Nazionali di Lavoro, CCNL) tenham sido muito fortes, com maior incidência de contratação no âmbito da empresa ou do território. Se a tendência ao aumento na negociação chamada de "segundo nível" (empresa e território) é bastante forte nas declarações e nas intenções dos empresários, a realidade - pelo menos no caso italiano - mostra uma baixa difusão de negociação no campo da empresa; isso também se deve à alta fragmentação das empresas italianas. Como destaca Pellegrini (2015), se a contratação coletiva nacional cobre $95 \%$ das empresas, a de segundo nível (de empresa, território, grupo empresarial, única unidade de produção) representa apenas 15,8\%, mas, nas grandes empresas (com mais de 500 empregados), atinge $65,6 \%$, mais no Norte da Itália $(19,6 \%)$ e menos no Sul $(6,1 \%)$. A presença da negociação de segundo nível é indicadora também da presença sindical; em $60 \%$ das

ao restante da experiência europeia, a livre contratação coletiva foi sempre favorecida no que diz respeito à regulamentação normativa, ao menos até os anos 1990 , quando os governos conservadores tornaram o sistema das relações industriais um dos mais prescritivos juridicamente. Ao mesmo tempo, nos anos 1990, foi reduzida a cobertura da contratação coletiva. 
empresas com mais de 500 empregados há organismos sindicais no chão de fábrica.

A elevada fragmentação da estrutura produtiva italiana, como no caso do Japão, não tem facilitado, desse ponto de vista, a sindicalização ${ }^{3}$. O "Estatuto dos Trabalhadores", por exemplo, é aplicado apenas nas fábricas com mais de 15 empregados ${ }^{4}$.

Se na experiência da Europa ocidental o sindicato alcançou um crescimento significativo nas mobilizações dos anos 1960, com um pico de conflitos no período de 1968-1973, no caso da Itália, pode-se afirmar que, mais do que um pico, trata-se de uma explosão que será constante por toda a década de 1970 e que levará ao surgimento de uma temporada de novos direitos sindicais com aprovação, por exemplo, do próprio Estatuto dos Trabalhadores ${ }^{5} \mathrm{em}$

\footnotetext{
3 À elevada fragmentação da estrutura produtiva italiana existe ao menos duas possíveis explicações. A primeira, histórica, depende do apoio da Democracia Cristã às pequenas empresas (do ponto de vista fiscal e legislativo), com o escopo de conter o crescimento da grande indústria, em que a presença sindical e do Partido Comunista eram muito fortes (cf. Fabrizio Barca, 1999). O segundo motivo depende, ao menos no setor industrial, da difusão, particularmente a partir dos anos 1970, de um modelo de especialização flexível, típico das empresas com maior capacidade de responder às inovações de produto e de processo, com a diversificação do mercado de consumo (cf. Piore e Sabel, 1984). No caso japonês, a difusão das pequenas empresas no setor industrial está ligada historicamente à ampla difusão dos produtos semiacabados para a grande indústria. O modelo de produção japonesa apresenta, portanto, um nível de de-verticalização muito elevado que está na origem do conceito de produção enxuta (lean production), sobretudo pela existência de uma ampla rede de fornecedores (keiretsu) que servem como apoio dos seis principais complexos industriais do país (Harrison, 1994).
}

${ }^{4}$ Com base nos dados mais recentes disponibilizados pelo Istituto Nazionale di Statistica (ISTAT) em 2014, de um total de 11,3 milhões de trabalhadores subordinados, 25,4\% estavam empregados em empresas com até nove funcionários e 25,6\% em empresas com até cinquenta funcionários.

${ }^{5}$ Com isso, entre outras coisas, foram introduzidas por lei as representações sindicais empresariais (RSA) e a Assembleia dos trabalhadores. O Estatuto sanciona um conjunto de direitos dos trabalhadores dependentes (liberdade sindical), afirma, em termos de direito, a presença do sindicato em fábrica e proíbe a atividade antissindical. De modo mais geral, o Estatuto sanciona, de fato, o ingresso da Carta Constitucional nas fábricas, dado que desde então se afirmava que a Constituição parava diante dos portões das fábricas. O Estatuto estabelece, além disso, sobretudo no artigo 18, que o licenciamento pode ocorrer só por justa causa, e um claro procedimento para que seja exigível, além de prever que o sindicato dê assistência ao 
1970 (Baglioni, 1989). Nesse sentido, Pizzorno observa que a formação de uma nova identidade não poderia ser mais do que transitória e, portanto, destinada a encontrar uma interrupção (Pizzorno, 1977), como efetivamente ocorreu nas décadas seguintes.

Fica bastante claro que nesse período o sindicato italiano está animado por um grande fervor de solidariedade, de um sólido classismo, de forte impulso igualitário e da ideia-força da unidade sindical. Tratam-se de aspectos que hoje parecem todos ultrapassados, com exceção da referência ao tema da solidariedade, tendo em conta que a questão da unidade sindical desapareceu depois de ser, novamente, proposta nos últimos anos ${ }^{6}$.

Este artigo tenterá, de forma sintética, ilustrar as principais tendências que têm caraterizado a evolução do sindicato italiano do final dos anos 1970 até hoje, abordando principalmente quatro temas: 1) a crise da conflitualidade sindical e da experiência do "sindicato dos conselhos"; 2) o nascimento de sindicatos autônomos extraconfedereis; 3) a reforma da contratação sindical e a instituição das RSU (Rappresentanze Sindacali Unitarie); 4) o atual quadro da sindicalização e a crise da representatividade que o sindicato está enfrentando em relação às mudanças do mercado do trabalho. As considerações finais contêm reflexões sobre o destino do sindicato italiano que revela uma tendência crescente para a prestação de serviços em detrimento da sua capacidade contratual e de mobilização.

trabalhador diante da empresa. É importante ressaltar que o estatuto era aplicável somente nas empresas com mais de quinze empregados. As recentes reformas do mercado de trabalho determinaram mudança quanto ao artigo 18, portanto, hoje, para os novos empregados contratados, pode-se proceder em qualquer momento o licenciamento, inclusive sem justa causa, com o único agravante de ressarcimento máximo de 24 mensalidades ao trabalhador em virtude do tempo de trabalho.

${ }^{6}$ A unidade sindical na Itália, entre CGIL, CISL e UIL, foi experimentada de 1972 até 1984 e teve algum êxito, sobretudo em certas categorias, como a dos metalúrgicos e dos químicos. Trata-se de um tema que volta periodicamente no debate sindical, mas ainda hoje é mais uma invocação do que uma real perspectiva. 


\section{A derrota sindical de novembro de 1980 e o declínio do sindicato dos conselhos}

O declínio do poder do movimento sindical italiano tem uma data símbolo, a do outono de 1980, quando termina o conflito entre a Fiat e os sindicatos dos metalúrgicos de Turim, após o anúncio da demissão de 15 mil empregados que se transformou em um acordo sindical posterior à paralisação de 24 mil trabalhadores por um tempo prolongado ${ }^{7}$, mas, sobretudo, na plena volta da empresa ao controle da fábrica e da organização do trabalho. Esse evento anunciava o que um notável sindicalista dos metalúrgicos da CGIL, à época, Claudio Sabattini, chamaria mais tarde de início da "restauração italiana”, referindo-se às mudanças ocorridas, a partir daquele momento, nas relações sindicais e no papel do sindicato nas fábricas e na sociedade italiana (Sabattini e Polo, 2000).

A crise da "centralidade da classe operária" perda de autoridade moral e crise da centralidade política e da hegemonia social que o sindicato sofre desde o começo da década de 1980, talvez seja só a manifestação mais evidente de uma crise que advém de vários fatores, que incluem, por exemplo, de um lado, a crítica do "igualitarismo salarial" praticado pelo sindicato (Accornero, 1992) e, de outro, os primeiros efeitos de uma mudança na composição setorial da ocupação que depende, em parte, da reestruturação do aparelho industrial e de um forte desemprego operário mas, sobretudo, da expansão do setor terciário.

\footnotetext{
7 A derrota do sindicato surge claramente quando, pela primeira vez na cidade, uma manifestação de cerca de 40 mil funcionários e gerentes da Fiat, em Turim, pede o fim do protesto dos trabalhadores e a retomada do trabalho. Se bem que o número efetivo tenha sido sempre um tema controverso, "a marcha dos 40 mil" estabeleceu-se no imaginário coletivo como um evento simbólico daquele período (Sabattini e Polo, 2000).

8 Trata-se de um conceito particularmente relevante no seu significado sociológico. Essa "centralidade" se refere àquela de um sindicato - o metalúrgico - que tem nesse período maior capacidade de negociação e que consegue, com a sua ação, influenciar as plataformas sindicais das outras categorias em relação à renovação dos contratos coletivos de trabalho e mobilizar-se sobre questões de interesse geral (saúde, pensões, direitos à moradia etc.), agregando outras entidades não sindicais.
} 
Nesse sentido, de acordo com Accornero (1992, p. 14), "dos últimos anos 60 aos primeiros anos 90 o movimento sindical italiano tem cumprido uma parábola histórica impressionante". Essa parábola está referida ao processo de decréscimo da influência pública do sindicato que, nos últimos anos, tem se reduzido bastante e que depois do início da década de 1990 diminuiu ainda mais.

O período de ascensão e de legitimidade do sindicato italiano durou, para Accornero, do "outono quente" (autunno caldo) de $1969^{9}$ até a chamada "escolha do EUR" ( scelta dell'EUR) em 1978, assim nomeado pela assembleia sindical, que, naquela ocasião, sancionou a escolha do sindicato italiano pela aceitação da "austeridade" nas revindicações salariais para lidar com a crise econômica daquele período e para fazer frente às pressões que chegavam do governo para combater o crescimento da inflação.

A crise do sindicato é também de seus organismos de representação no chão da fábrica: os conselhos de fábrica. Esses nasceram no contexto da crítica das comissões internas com o objetivo de unificar as ações dos vários sindicatos e de reforçar o poder de negociação nos locais de trabalho (Carrieri, 1995; Romagnoli, 1976). A crise desses organismos se manifesta nos anos 1980, num contexto de profundas mudanças das relações sindicais e de retrocesso da conflitualidade sindical: o conselho de fábrica aparece como um instrumento antigo e autorreferencial, incapaz também, em muitas grandes empresas, de renovar suas lideranças sindicais. A crescente competição entre as confederações, de um lado, e certa perda de representatividade, de outro, levou à falha na renovação dos conselhos de fábrica, a experiência

\footnotetext{
9 Este período, que na verdade tem início alguns anos antes, viu um forte protagonismo da classe trabalhadora em suas reivindicações salariais e contra o projeto de reforma do sistema da aposentadoria avançado pelo governo. Por muitos anos a expressão "outono quente" descrevia habitualmente um período de mobilizações e conflitualidade dos sindicatos na Itália.
} 
mais inovadora do sindicato italiano dos anos 1970 que foi substituída, no início dos anos 1990, pelas Rappresentanze Sindacali Unitarie (RSU).

Uma contribuição para a crise de ação sindical vem também dos diferentes posicionamentos das confederações sobre o tema da política salarial. Se a derrota sindical do outono de 1980 marca a primeira ruptura entre as confederações que tiveram, naquele período, uma unidade mais formal que substancial, isso se torna mais evidente em 1984 (e no referendo do ano seguinte), quando as divisões sindicais se tornam agudas entre CISL e UIL, de um lado, e CGIL, de outro, sobre o tema da "escala móvel" ( scala mobile) ${ }^{10}$, depois da decisão do governo de reformar o mecanismo de ajuste automático dos salários em relação à inflação que vê mais disponíveis CISL e UIL à frente do projeto de reforma do governo (Filippini, 1988).

Do outro lado, observa-se a diminuição da "reserva de lealdade" (Negt, 1988), enquanto nos acordos propostos 294 pelos dirigentes sindicais, em algumas categorias, por ocasião da renovação dos CCNL e submetidas ao referendo, manifesta-se um aumento dos votos contrários. Em geral, o sindicato vai assumir um perfil cada vez mais "institucional”, mas também ele acusa uma perda de poder. Questões como as críticas às greves nos serviços públicos e o pedido de encerramento de fábricas poluidoras ganham um crescente consentimento entre a população - fator que revela uma inclinação daquela hegemonia que o sindicato parecia ter na sociedade italiana. Os anos 1980 são considerados um período de mudança nos costumes sociais e políticos, e, no contexto de uma afirmação

\footnotetext{
${ }^{10}$ A "escala móvel" era um instrumento econômico da política salarial destinada a ajustar de forma automática os salários de acordo com os aumentos de preços. Foi introduzida na Itália em 1945, após um acordo entre a Confederação Geral da Indústria Italiana e a CGIL; depois de sua extensão, em 1975, foi abolida no início dos anos 1990. Em 1984, o governo propôs um corte de $4 \%$ desse índice com um decreto que o então Partido Comunista Italiano tentou extinguir com um referendo popular no ano seguinte. No referendo de junho de 1985, no entanto, prevaleceu a proposta do governo (54,3\% de votos favoráveis) apoiada pela CISL e UIL.
} 
de comportamentos mais relacionados ao consumo e de uma nova suposta modernização da sociedade italiana, o sindicato começa a ser percebido como organização corporativa e burocrática. Nesse aspecto, essa crítica ao sindicato se fortalece nos anos mais recentes, de maneira instrumental, sobretudo depois que as várias reformas do mercado do trabalho, promovidas a partir do início dos anos 1990, aumentaram o número de trabalhadores excluídos dos benefícios da legislação trabalhista e das coberturas dos contratos coletivos nacionais e/ou mal representados pelos sindicatos.

\section{O nascimento dos sindicatos autônomos: uma alternativa ao sindicato confederal?}

Outro indicador da crise do sindicato italiano nos anos 1980 é representado pelo nascimento de outras organizações sindicais (de base, autônomas etc.) na tentativa de desafiar o monopólio da representatividade sindical das três confederações (CGIL, CISL, UIL). Por exemplo, a formação do sindicato dos maquinistas de trens, o Sindicato Autonomo dei Macchinisti Uniti (COMU), em 1987; dos professores nas escolas com os comitês de base (COBAS - Comitati di Base), em 1986; dos controladores de tráfego aéreo e dos pilotos de avião, a Associazione Nazionale Professionale Aviazione Civile (ANPAC), entre outros. Os primeiros dois são de origem de esquerda e apontam uma crise no modelo de solidariedade promovido até aquele momento pelas confederações. De outra parte, representa também a tentativa de reanimar o conflito sindical na busca de melhorias econônomicas, ainda que essa perspectiva pudesse parecer mais corporativa.

De qualquer maneira, o nascimento dessas organizações não responde apenas à diferenciação da demanda particularista que vem dos diferentes componentes do mundo do trabalho, mas reflete também uma dificuldade das confederações, tendo em conta as mudanças culturais que começam a se tornar mais evidentes na sociedade italiana, em 
particular com referência ao tema da solidariedade entre os vários setores do mundo do trabalho. Concordando com Accornero (1992, p. 17):

É muito fácil condenar esses impulsos como "corporativos". Essas novas experiências sindicais foram ajudadas pelo comportamento irresponsável do empregador público, que demorou a aplicar os acordos assinados com as confederações e aceitando as organizações que não aceitavam ou não respeitavam os "códigos de autoregulação" das greves. Organizações autônomas como as COBAS e as GILDAS nasceram na sequência de um protesto contra o governo, que tem se manifestado por causa da facilidade de exibir uma identidade bloqueando um serviço público, em vez da necessidade de afirmar um interesse negligenciado pelas confederações.

A falta de aplicação normativa dos artigos 39 e 40 da Carta Constitucional italiana de 1948 - ou seja, a ausência de regras para verificação da representatividade da assinatura dos acordos - possibilitou, nesse período, que várias organizações autônomas reivindicassem a titularidade da assinatura dos acordos coletivos separados, mesmo sem qualquer representação efetiva (ainda que não houvesse representantes eleitos nos locais de trabalho, que fosse baixo número de filiados, etc.). Trate-se de um problema ainda hoje presente e que tem levado à existência de um número maior de CCNL, simplesmente pela assinatura aposta por associações patronais e sindicatos dos trabalhadores sem representatividade (Olini, 2016).

$\mathrm{Na}$ atualidade, o fenômeno do sindicato autônomo não só resiste, mas parece aumentar sua difusão, sobretudo no setor público - onde as confederações permanecem majoritárias como no resto do setor privado - e em alguns setores terciários ou entre atividades como logística, em que a presença de trabalhadores estrangeiros é hoje predominante e 
se destaca, em particular, a atuação dos sindicatos de base, como a pequena Confederação da USB (Unione Sindacale di Base). Ao mesmo tempo, nos últimos anos, novas confederações têm incrementado a presença no cenário sindical italiano, algumas com perfil político mais evidente, como a UGL (Unione Generale del Lavoro, antiga CISNAL Confederazione Italiana Sindicati Nazionali Lavoratori -, confederação historicamente ligada ao Movimento Social Italiano herdeiro do partido fascista), ou tendencialmente mais corporativo como a CISAL (Confederazione Italiana Sindacati Autonomi Lavoratori). Em geral, estimase que essas confederações e outras pequenas organizações, com presença mais segmentada entre as várias atividades econômicas, podem reunir entre dois e três milhões de filiados ${ }^{11}$, mas trata-se de uma estimativa difícil de verificar.

\section{Anos 1990: um novo padrão de relações industriais e 0 papel da contratação coletiva nacional de categoria}

No início dos anos 1990 as chamadas "partes sociais" (sindicatos, associações representativas de empregadores e governo) têm inaugurado um novo padrão de relações industriais, de tipo neocorporativo, baseado na "concertação" entre os principais atores econômicos e sociais ${ }^{12}$. O objetivo desse modelo era chegar a um "pacto entre os produtores"

11 O número exato de afiliados aos sindicatos extraconfederais não é muito preciso. Os dados se baseiam, principalmente, nas declarações dos sindicatos. O número divulgado pela CISL, por exemplo, é de 1,7 milhão de filiados. Nos últimos anos, no entanto, as confederações CGIL, CISL e UIL têm encaminhado um processo, com a colaboração do Instituto Nacional da Previdência (INPS), que deverá trazer um quadro mais claro sobre essa questão. As três confederações envolveram o INPS, pois as empresas comunicam a esse órgão alguns dados, entre os quais, o número de filiados ao sindicato. Deve-se esclarecer, no entanto, que não se trata de uma informação a ser comunicada obrigatoriamente por parte das empresas ao INPS.

12 A Itália tem representado sempre um dos níveis mais baixos de institucionalização da concertação na comparação com os países da Europa do Norte (Valenti, 2014). No caso da Itália pode se falar, nesse sentido - ao menos na experiência dos anos 1970 - de um "corporativismo instável" pelas divisões entre sindicatos e pela falta de governos pro labour em um contexto de elevada sindicalização (Regini, 2007). 
baseado na contenção de aumentos salariais pelo desaparecimento definitivo da "escala móvel", substituída por uma inflação programada de referência para renovação dos contratos coletivos. Os acordos dos anos de 1992-1993 confirmam também o duplo nível de negociação nacional, de categoria e empresarial; o segundo, em particular, tem como objetivo assegurar uma redistribuição dos ganhos econômicos obtidos pelas empresas nas quais a maior produtividade do trabalho tem assegurado esse resultado. A ideia central era a de que o CCNL deveria proteger o trabalhador, principalmente da inflação, e que os incrementos variáveis de salários fossem reservados à negociação empresarial.

O novo modelo de relações industriais traz uma inovação significativa com o ingresso das RSU (Rappresentanze Sindicali Unitarie) nos locais de trabalho, substituindo os delegados dos velhos conselhos de fábrica. Eles são eleitos em cada empresa com mais de quinze empregados e têm capacidade de iniciativa sobre várias questões que, no âmbito da empresa, podem ser melhoradas com respeito às regras fixadas no $\mathrm{CCNL}^{13}$. $\mathrm{O}$ forte monopólio das três confederações confirma-se também pelo fato de que, em cada empresa, um terço deles é nomeado pelos sindicatos confederais, independentemente do resultado das eleições, em virtude do princípio muito contestado na

\footnotetext{
13 A ideia é que a negociação no domínio da empresa pode prever derrogações ao contrato coletivo nacional de categoria somente se trouxer melhorias no plano salarial e do horário de trabalho. A título de exemplo, um contrato empresarial ou de grupo não pode prever uma redução da indenização paga pelas horas extraordinárias com relação ao fixado pelo CCNL (Contratto Collettivo Nazionale di Lavoro), ou a possibilidade de assumir, para determinadas ocupações, trabalhadores com nível de enquadramento contratual inferior ao previsto pela CCNL. A experiência prática demonstra que boa parte das contratações de segundo nível serviu às empresas para a mudança dos regimes de horários de trabalho, inclusive por meio da utilização do sistema banco de horas. Justamente essa rigidez do CCNL, por exemplo, levou a Fiat, em 2011 - hoje FCA -, a abandonar o CCNL dos metalúrgicos e criar um contrato coletivo exclusivo para todas as unidades da empresa, derrogando, dessa forma, respeito ao CCNL metalúrgico e prevendo aumento das horas de extraordinário, sem contratar com o sindicato ou definindo uma estrutura dos aumentos salariais não incidentes no piso salarial.
} 
jurisprudência da "maior representatividade" destas ${ }^{14}$. Todavia, por conta dessa controvérsia, o recente acordo entre as confederações sindicais e a Confidustria (a maior associação das empresas) tem definido um texto único sobre a representatividade sindical, de 14 de janeiro de 2014, que tem eliminado à quota de um terço, estabelecendo um sistema eleitoral totalmente proporcional pelas eleições das RSU.

$\mathrm{O}$ aparecimento das RSU tem sido muito importante na renovação das dinâmicas da ação sindical nos locais de trabalho, mas seu potencial resulta sempre limitado. Ainda hoje - seja pela fraca negociação sindical no âmbito a empresa, à exceção das grandes empresas, seja pela maior presença de dirigentes sindicais e funcionários -, agora "verdadeiros profissionais da política" que, muitas vezes, acabam relegando as RSU tão somente à resolução de problemas básicos (Braga e Carrieri, 2007). Assim, as RSU permanecem pouco valorizadas. Isso é ainda mais significativo se considerarmos que a crise da concertação social, de modo especial ao nível central, impõe uma rediscussão do padrão confederal e da sua difusão, aumentando, por conseguinte, a importância da ação sindical nos locais de trabalho e no âmbito territorial (Feltrin, 2015).

\section{Crise de representatividade, redução da sindicalização entre os ativos e novas formas de sindicalização}

Há quem tenha argumentado que a crise de representatividade do sindicato italiano aumentou pari passu ao incremento das formas atípicas de emprego e com a redução do espaço coberto pela contratação coletiva. Assim, ainda que a redução da taxa de sindicalização seja um aspecto que

\footnotetext{
14 Em 1996 foi instituída por lei a figura do Rappresentante dei Lavoratori per la Sicurezza (RLS), que, ao contrário do RSU, deve ser eleito obrigatoriamente a cada três anos em todas as empresas com mais de quinze trabalhadores. As empresas menores têm previsão de eleição ou devem nomear pelo sindicato de RLS com base no território ou no setor econômico.
} 
caracteriza os principais países capitalistas, as motivações que teriam levado ao decréscimo do percentual de sindicalizados não têm uma causa última. A mudança na estrutura produtiva e a perda de centralidade da classe trabalhadora do setor industrial é um dos motivos, mas não é o único. Também nos setores mais sindicalizados, como a indústria, é necessário considerar a mudança que o management promoveu nos anos 1980 (Becchi Vollidà e Negrelli, 1986), sobretudo no final da década, com a introdução do padrão japonês na indústria automobilística (Bonazzi, 1993; Coriat, 1993). No caso da Itália, a experiência da Fiat é, nesse sentido, particularmente relevante, considerando a influência dessa empresa na difusão de práticas inovadoras nas relações industriais do país.

Esses tipos de práticas ainda são bem-sucedidas nos dias de hoje, graças à pluralidade das organizações sindicais presentes na esfera da empresa. Por exemplo, as organizações de categoria dos metalúrgicos da CISL e da UIL, respecti300 vamente FIM e UILM, sempre tiveram uma postura mais aberta para a empresa no âmbito da partilha do padrão produtivo e das relações sindicais - isso se deve também à tradicional baixa propensão ao conflito entre elas. Ao mesmo tempo, é importante considerar que o perfil do trabalhador metalúrgico mudou: apresenta nível de escolaridade maior e, com isso, mais expectativas de carreira, e baixo nível de politização devido ao desaparecimento das grandes organizações políticas. É nesse contexto que um dos mais importantes gerentes do antigo grupo Fiat afirmou, recentemente, que a competição, hoje, não é mais entre empresas, mas entre os trabalhadores e que, por isso, ambos devem se unir na competição internacional (Rebaudengo, 2015).

Em 2014 a taxa de sindicalização na Itália era de $33,4 \%{ }^{15}$. Se considerarmos os trabalhadores do setor público

\footnotetext{
${ }^{15}$ Se observarmos este valor para o setor privado e para o setor público são, respectivamente, $31,9 \%$ e $37,7 \%$; em 1979 , o setor privado era aquele que apresentava
} 
e privado filiados às três principais confederações (representavam 43,3\%, em 1979), aquele percentual, no entanto, sobe a $37 \%$ se incluirmos os filiados aos sindicatos autônomos. Nos anos 1980, representavam entre 40 e 45\%, em posição intermediária entre os países do Norte da Europa (Suécia, Áustria, Alemanha, Inglaterra) e os do Centro e Sul europeu (Suíça e França, Grécia, Espanha, Portugal).

Se observarmos a tendência da sindicalização, nota-se que o associativismo sindical atingiu seu auge no final dos anos 1970 e, nos dias de hoje, a densidade sindical tende a abaixar. Isso não significa que o número de filiados, em sua totalidade, seja diminuto em valores absolutos, já que o número de aposentados entre os filiados cresceu significativamente. Entre 1981 e 2017 o número total de filiados das três principais confederações (CGIL, CISL e UIL) passou de cerca de 8,8 milhões para quase 12 milhões. Esse incremento de trabalhadores sindicalizados foi, basicamente, devido ao aumento dos aposentados que triplicou em 2017, comparando-se ao número de inativos filiados a essas confederações no início dos anos 1980. Após a primeira fase de redução dos filiados, entre 1980 e 1986, manteve-se certa estabilidade até 1992, havendo nova redução até 1998 e novo aumento até aos últimos anos, que conforme Feltrin (2015) poderia ser atribuído à crise econômica que tem aproximado mais os trabalhadores que precisam de assistência - tendência que parece contrária àquela que, na literatura, relaciona o incremento da sindicalização como resultado de um processo pró-cíclico.

No período analisado, o número de trabalhadores ativos e aposentados é quase equivalente, mas o dado que desperta mais atenção é a redução dos filiados entre os "ativos" do setor privado, se excluirmos os trabalhadores estrangeiros: entre 1981 e 2017 , passam de $64 \%$ para $36 \%$;

a maior taxa de sindicalização, 44,5\% contra o 39,7\% do setor público (Carrieri e Feltrin, 2016). 
já a sindicalização entre os aposentados passa de 20,2\% para 43,9\% ${ }^{16}$; há decréscimo entre os empregados do setor público, nesse período, de $15,7 \%$ para $12,3 \%$, enquanto os trabalhadores estrangeiros do setor privado passam de $0,8 \%$ em 1991 para 7,4\% em 2017 (Gráfico 1).

\section{Gráfico 1}

Filiados aos sindicatos confederais (CGIL, CISL, UIL) por setor em valores absolutos, anos selecionados

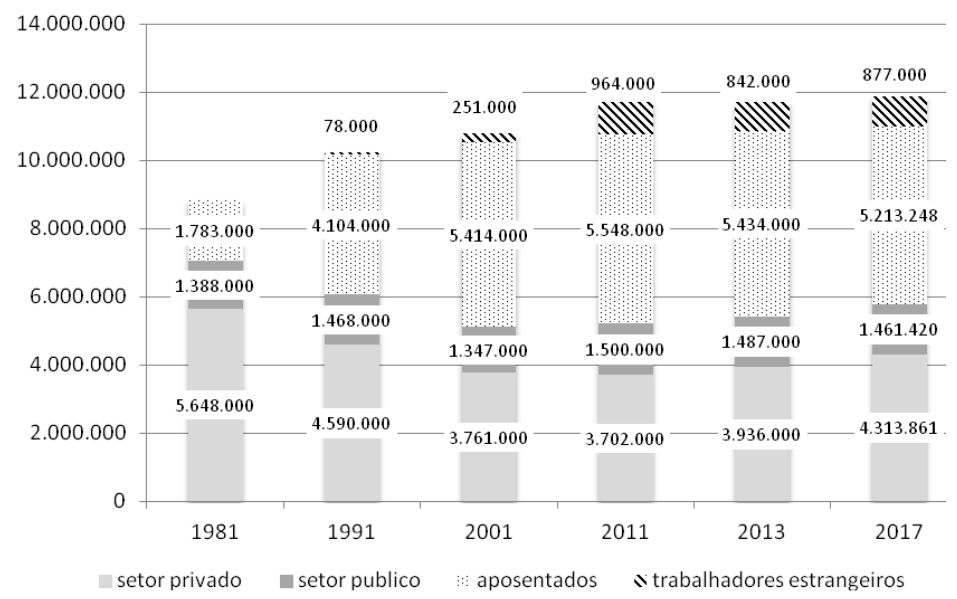

Fonte: Feltrin (2015). Para 2017, nossa elaboração sobre dados das confederações (para trabalhadores estrangeiros) se trata de uma estimativa a partir da variação da taxa de ocupação.

No final dos anos 1990 o aumento dos filiados ao sindicato é mais forte no setor terciário, especificamente no setor público e no comércio, enquanto permaneceu estável nos outros componentes do terciário. A indústria tem recuperado

\footnotetext{
16 "A dinâmica global não é a mesma entre as três confederações. Na CGIL já em 1993 os aposentados representavam a maioria entre os sindicalizados, tendência que se mantém até hoje chegando, em alguns anos, a anos a $55 \%$ do total dos filiados; na CISL os aposentados superam os ativos só a partir de 1998 e apresentam uma situação mais equilibrada; a composição da UIL é completamente distinta, com uma presença maior dos ativos, sempre acima de $70 \%$ de seus filiados" (Carrieri e Feltrin, 2016, pp. 33-34).
} 
também certo número de filiados, no entanto, devido às perdas pregressas e à crise iniciada em 2008, não conseguiu, nem de longe, se recuperar do "cataclisma" da dessindicalização. O mesmo pode ser dito dos trabalhadores na construção. De modo geral, entre 1981 e 2014, o número de filiados dos setores industrial e rural ${ }^{17}$ caiu de 3,4 milhões para 1,9 milhão, de 48,9\% para $31,4 \%$ do total de filiados das três confederações. Os filiados do comércio passaram de $5 \%$ a $15 \%$, e aqueles que trabalham no terciário privado cresceram de $20,1 \%$ para 29,9\% (Carrieri e Feltrin, 2016). O resultado é que, hoje, a categoria que conta com o maior número de filiados é o setor público, seguida pelo comércio, que, até o final dos anos 1990, ficava nas últimas posições em termos de sindicalização.

A questão dos trabalhadores estrangeiros representa um aspecto novo nas dinâmicas da sindicalização. Em 2017 eles representaram $7,4 \%$ do total de filiados das três confederações: 20,3\% entre os empregados do setor privado (quase 900 mil afiliados). Em 2011, no entanto, o peso desse setor era anda maior: respectivamente, 8,2\% e 25,6\%. Nesse sentido, a sindicalização dessa categoria de trabalhadores resultou mais sustentada do que a dos trabalhadores italianos, sobretudo se considerarmos a forte presença deles em alguns setores da indústria, como o dos metalúrgicos no Norte do país, onde a presença sindical sempre foi forte (Mottura, Cozzi e Rinaldini, 2010). Em geral, é nas atividades em que a presença dos trabalhadores estrangeiros é maior que o número de filiados é mais alto: serviço de cuidados pessoais, construção, indústria agroalimentar, comércio.

Como explica Feltrin, em última análise, a força do sindicato italiano em conservar sua representatividade parece depender mais de sua capacidade organizativa do que da negocial, em termos de ganhos de resultados pela classe trabalhadora:

\footnotetext{
17 Os trabalhadores rurais se referem aqui aos empregados da indústria agroalimentar e aos trabalhadores de cultivo e coleta de produtos agrícolas.
} 
A performance [do sindicato] italiano é comparativamente mais positiva graças a uma capacidade organizativa melhor, confirmada também na permanência de taxas de sindicalização superiores a $30 \%$, da vivacidade do serviço sindical, da capilaridade da sua presença territorial, da solidez da estrutura patrimonial e dos equilíbrios financeiros ${ }^{18}$ (Feltrin, 2015, p. 201).

Assim, se observarmos os indicadores, como a taxa de filiação ao sindicato italiano, há um aparente declíno (Feltrin 2005, 2010), mas, se voltarmos a olhar para o "sindicato como organização”, aparecerá em boa saúde ${ }^{19}$. Se depois considerarmos o conjunto dos filiados, incluindo aqueles das outras confederação (as chamadas extraconfederais), o número completo de filiados (incluídos os aposentados) atinge quase 15 milhões, mas a incerteza desse dado sugere tomá-lo como estimativa.

Carrieri e Feltrin (2016) preconizam que a retomada de adesão ao sindicato na Itália, na segunda metade da década de 1990, depende das quatro variáveis independentes: o melhor andamento do mercado do trabalho, exceto a crise de 2008; a variável organizativa própria de cada sindicato;

\footnotetext{
18 Nos últimos anos esse tema se tornou mais problemático. No contexto de crise do sistema político também o sindicato não está imune às criticas e denúncias de casos de má administração de seus balanços (Liviadotti, 2008). Mesmo a decisão de revisão da estrutura territorial, como a da CISL, que reduziu as federações provinciais de 115 para 72, responde também a problemas de contratação de recursos econômicos, além de necessidades organizativas como a agregação de algumas categorias da indústria antes separadas (também pela redução do emprego nos ramos únicos da indústria).

19 É importante ressaltar que já no final dos anos 1970 um estudioso do sindicato e também dirigente sindical da CISL, Bruno Manghi (1977), analisou o papel do sindicato italiano utilizando a expressão "declinar crescendo". Segundo os autores citados, a redução dos afiliados entre os trabalhadores ativos (ou seja, entre os empregados) não significou redução da importância do sindicato, já que o número dos afiliados aumentou por efeito do crescimento destes entre os trabalhadores aposentados e porque o aumento dos serviços oferecidos pelos sindicatos cresceu, consentindo, inclusive, maiores disponibilidades econômicas (por exemplo, assistência fiscal, assistência para os procedimentos de aposentaria, para as questões ligadas às doenças profissionais e aos infortúnios).
} 
os serviços sindicais (assistência fiscal e outras atividades) e, por último, uma variável "político-welfarista" ${ }^{20}$, que pode ter incrementado a proximidade dos trabalhadores ao sindicato engajado contra a redução do sistema de proteção social pelas reformas introduzidas pelos últimos governos.

A literatura sociológica que discorre sobre as características dos filiados às organizações sindicais na Itália nos anos mais recentes não é muito ampla e, em geral, o tema do sindicato não é muito frequente na literatura sociológica - exceção de alguns estudiosos que têm produzido importantes trabalhos de pesquisa nos últimos anos, entre eles, Carrieri e Feltrin (2016).

De outra parte, se considerarmos os dados fornecidos pelas confederações, confirma-se, por exemplo, a baixa presença de jovens entre os filiados: são $19 \%$ com menos de 35 anos na CGIL e $16 \%$ na CISL, a UIL declara ter um terço dos afiliados com menos de 45 anos $^{21}$. Ao contrário, considerando o peso dos aposentados, os filiados com mais de 60 anos são $36 \%$ na CGIL e $41 \%$ na CISL.

\footnotetext{
${ }^{20}$ O sistema de welfare italiano pode ser classificado em um modelo "meritocrático-remunerativo" (Paci, 1982), em que o sistema de proteção se baseia não no direito de cidadania, mas na proveniência a uma determinada categoria socioprofissional. Trata-se de um sistema de assegurações obrigatórias garantidas e financiadas em parte pelo Estado, em sua maior parte por contribuições que por entradas fiscais. As contínuas reformas deste sistema de welfare italiano, que torna ainda mais seletivo o acesso a alguns benefícios, podem ter aumentado o recurso às estruturas do sindicato do ponto de vista burocrático, enquanto sob o ponto de vista político, a adesão ao sindicato por parte dos trabalhadores seria diretamente função da oposição do sindicato às medidas de reforma do sistema de welfare.

${ }^{21}$ Sobre o porquê de os jovens se inscreverem menos ao sindicato, as pesquisas empíricas sugerem que isso acontece porque eles "trabalham mais frequentemente nas pequenas empresas não sindicalizadas (da indústria ou do terciário) e porque contratados mais frequentemente com contratos de trabalho por prazo determinado ou contratos de forma diferentes do trabalho subordinado" (Carrieri e Feltrin, 2016, p. 48). De acordo com os autores citados, existiriam também outros aspectos culturais e profissionais que podem influir sobre a propensão à sindicalização, como o maior compartilhamento dos objetivos produtivos das empresas (Bubbico, 2003; Franchi, 1991).
} 
Um indicador que reflete, ainda mais, essa situação crítica do sindicato se refere ao número de filiados nas organizações específicas de categoria (conhecidas como os sindicatos dos trabalhadores atípicos) que cada confederação instituiu há vinte anos para responder ao aumento do emprego precário no mercado do trabalho italiano. O número total declarado em 2017 é pouco mais de 200 mil filiados (Tabela 1) e, se considerarmos o total dos trabalhadores com contrato de trabalho por tempo determinado (quase 2,9 milhões para uma ocupação total na Itália de pouco mais de 23 milhões de trabalhadores no ano de 2017), a taxa de sindicalizado desse segmento é aproximadamente de $7,5 \%{ }^{22}$.

Tabela 1

Trabalhadores atípicos filiados às organizações sindicais de categoria das centrais sindicais em 2017

\begin{tabular}{ccccc}
\hline $\begin{array}{c}\text { Entidade } \\
\text { sindical }\end{array}$ & $\begin{array}{c}\text { Descrição contida } \\
\text { na sigla da } \\
\text { entidade }\end{array}$ & $\begin{array}{c}\text { Número } \\
\text { de filiados }\end{array}$ & $\begin{array}{c}\text { Número total de } \\
\text { filiados à confederação } \\
\text { (excluídos aposentados) }\end{array}$ & $\begin{array}{c}\text { Incidência } \\
\text { \% sobre } \\
\text { filiados total }\end{array}$ \\
\hline NIDIL CGIL & $\begin{array}{c}\text { Novas identidades } \\
\text { de trabalho }\end{array}$ & 107.403 & 2.772 .928 & 3,9 \\
\hline $\begin{array}{c}\text { UILTEM } \\
\text { UIL }\end{array}$ & $\begin{array}{c}\text { Trabalhadores } \\
\text { temporários, } \\
\text { autônomos, atípicos } \\
\text { e com partida IVA }\end{array}$ & 70.935 & 1.377 .963 & 5,1 \\
\hline $\begin{array}{c}\text { FeLSA* } \\
\text { CISL }\end{array}$ & $\begin{array}{c}\text { Subministrados, } \\
\text { autônomos e atípicos }\end{array}$ & 41.601 & 2.267 .046 & 1,8 \\
\hline TOTAL & & 219.939 & 6.417 .937 & 3,4 \\
\hline
\end{tabular}

* Federazione Lavoratori Somministrati Autonomi Atipici

Fonte: elaboração própria, a partir dos dados das confederações; pela FeLSA CISL dados de 2016.

\footnotetext{
${ }^{22}$ No entanto, é necessário afirmar que nem todos os empregados com prazo determinado devem necessariamente se inscrever nessas organizações, uma vez que os empregados em contrato de prazo determinado ligados diretamente à empresa podem se inscrever regularmente no sindicato da própria categoria profissional. Os trabalhadores mencionados pelos sindicatos indicados na tabela incluem principalmente os temporários, autônomos, com contrato de colaboração e outros contratos "paras subordinados".
} 
Para alguns estudiosos, no entanto, seria um erro avaliar esse dado como extremamente negativo, considerando que muitas vezes, pelo curto prazo das relações de trabalho, o fato mais importante na dinâmica da relação sindical é a atividade de contato, suporte e informação que o sindicato é capaz de oferecer (Regalia, 2009). A relação crítica entre o sindicato e as novas profissões emergentes, muitas vezes estruturadas entre a subordinação e o trabalho autônomo, permanece, no entanto, presente. Pesquisas realizadas nos últimos anos mostram que os modelos organizacionais do sindicato não respondem às necessidades de representação que provêm desses novos componentes do mercado de trabalho, por exemplo, em relação aos serviços que eles precisam (Ciarini e Dorigatti 2017; Mingione et al., 2014).

Nos últimos anos, sobretudo nos contextos urbanos das grandes cidades, têm se formado experiências de lutas animadas por coletivos de base que unificam lutas sociais com aquelas por mais direitos dos trabalhadores. A experiência mais conhecida, ainda que circunscrita, é a denominada "Rede de San Precario" (Fumagalli, 2014), que está inserida no contexto do sindicato alternativo que, em alguns casos, tem se aproximado das práticas de luta dos sindicatos autônomos de esquerda. Essas lutas, como o encontro com os trabalhadores estrangeiros e, em geral, com os componentes mais marginais do mercado do trabalho, têm resultado muitas vezes em um dos aspectos mais interessantes. Mais recentemente, formas embrionárias de sindicalismo auto-organizado têm interessado os food-riders do Foodora e do Deliveroo, que trabalham em algumas grandes cidades italianas utilizando bicicleta como forma de transporte; são, geralmente, trabalhadores que recorrem a aplicativos digitais, como no caso do transporte privado organizado por Uber (Faioli, 2017).

Desse modo, a crise econômica que tem solapado a Europa nos últimos anos também tem favorecido formas de conflito político e social e novas formas de organização 
sindical dos trabalhadores mais precários no setor terciário e da nova economia, que alguns autores definiram por "sindicalismo social", um modo de organização dos conflitos que não investe apenas na esfera do trabalho, mas também nas políticas econômicas e sociais promovidas pelos governos comprometidos com políticas de austeridade (De Nicola e Quattrocchi, 2016; Doellgast et al., 2018). Essa hipótese refere-se, em parte, à proposta de "coligações sociais locais" (local social coalitions) funcionais para revitalizar a ação sindical de base, descrita por Fernie e Metcalf (2004), compartilhada por toda uma escola de pensamento anglo-americana.

\section{Destino do sindicato: sindicato de serviço ou sindicato de contratação?}

No curso dos últimos anos, as diferenças ${ }^{23}$ de perspectiva estratégica e política entre as confederações têm assumido uma direção bastante clara: a CGIL tem como proposta a 308 defesa do sindicato de direitos na tentativa de representar todos os setores do mundo do trabalho, ainda que sua presença seja fraca entre os segmentos de emprego mais precarizados A CISL adota um padrão de solidariedade que algumas vezes expira no corporativismo de categoria e, sobretudo, segue certo contratualismo político (ela se define como "sindicato de resultado") mais funcional à sua proposição de sindicato moderado e colaborativo. A UIL define-se como "sindicato dos cidadãos", nessa visão, os trabalhadores são vistos mais como usuários e consumidores que como produtores.

\footnotetext{
${ }^{23}$ Essas diferenças se referem à experiência mais recente das três confederações e não explica sobre sua origem. Sobre esse tema, é necessário observar que, no final do segundo conflito mundial, existia uma única grande confederação - a CGIL -, e poucos anos após a Segunda Guerra Mundial, saiu dessa central sindical a componente católica por expressa vontade da Democracia Cristã e dos americanos, interessados em criar um sindicato mais moderado. A mesma coisa aconteceu com relação à UIL, cujos dirigentes são provenientes da CGIL, por vontade do recém-nascido Partido Social Democrático Italiano. Já o Partido Socialista Italiano, que mantém seus militantes na CGIL, é mais moderado e aliado ao governo da Democracia Cristã desde os anos 1950.
} 
E o que acontece no espaço do sindicato extraconfederal? A confederação UGL, nascida em 1996 e que tem se beneficiado nos últimos anos da presença de um governo de centro-direita, tenta enconrar um espaço maior em vários segmentos do emprego, mas sua efetiva representatividade parece, ainda hoje, muito difícil de avaliar. A única confederação que conserva um caráter mais de sindicato de classe é a USB, que tem origem na fusão entre um sindicato de base fortemente radicado no setor público, a RdB (Rappresentanze Sindacali di Base) e o SdL (Sindacato dei Lavoratori), mais presente no setor privado. As outras confederações, como a Cisal ou as outras organizações sindicais de base, têm marcado presença principalmente na oferta de serviços, considerando que seu potencial de negócio é geralmente fraco e pouco representativo. No final, pode-se afirmar que até agora o "monopólio" da representação das três principais confederações permanece elevado. Isso não significa que não haja problemas de competição entre sindicatos em alguns setores como confirma a presença dos sindicatos autônomos em empresas do setor privado, nas quais, até poucos anos atrás, o sindicato independente estava completamente ausente.

Todas essas experiências sindicais e também aquelas do sindicato alternativo às três grandes confederações mostram que a componente dos serviços oferecidos (Feltrin e Maset, 2010; Leonardi, 2005), também para compensar a perda de financiamento derivado da redução de filiados entre os ativos, é uma característica comum. De acordo com Feltrin (2015), a análise das taxas de sindicalização na Europa, inclusive na Itália, evidencia particularmente que a representatividade dos sindicatos é mais forte onde se compensa o papel negocial com o oferecimento de serviços individuais aos trabalhadores e às pessoas com renda média baixa em relação a diferentes temas: inserção no mercado do trabalho, processos trabalhistas, formação profissional, suporte pela demanda de aposentadoria e seguro-desemprego, 


\section{obrigações tributárias ${ }^{24}$, lazer, entre outros ${ }^{25}$. No entanto, como observa Ida Regalia (2009, p. 122):}

altos níveis de filiação nem sempre indicam alta capacidade de representação e alta aprovação entre os trabalhadores: [...] o risco de uma ampliação ou apenas de uma filiação formal ou fictícia, como no caso das inscrições ligadas à obtenção de serviços, não estão totalmente conscientes. E, ao contrário, não é certo que os baixos níveis de filiação indiquem uma baixa capacidade de representação e um baixo acompanhamento sindical entre os trabalhadores.

Temos já evidenciado que um dos problemas mais relevantes no contexto sindical italiano está na fiscalização do nível de representação de cada confederação e, consequentemente, das organizações em nível de categoria, porque signatários dos $\mathrm{CCNL}^{26}$. Em tempos muito recentes as prin310 cipais confederações chegaram a um novo acordo sobre os conteúdos e os endereços das relações industriais e da contratação coletiva, em 27 de fevereiro de 2018, no qual estão confirmados os dois níveis da negociação (nacional, por empresa ou territorial), o reconhecimento da autonomia

${ }^{24}$ Esse serviço tem representado também uma modalidade de afiliação dos usuários: dessa forma, com essa absorção de sindicalizados, é possível manter estável o número de filiados garantindo, assim, uma importante fonte de financiamento. A decisão recente do governo de facilitar a compilação de declaração de renda via sistema on-line deve ter, no entanto, consequências negativas a esse respeito.

25 Todavia, se na Itália os serviços de assistência e tutela, bem como os serviços de tipo individual são oferecidos a todos, em países como Bélgica, França, Inglaterra, Alemanha, Suécia e Estados Unidos esses serviços são oferecidos apenas primordialmente aos filiados.

${ }^{26}$ Esclareço que, desde sempre, um dos problemas relativos ao tema da representação sindical na Itália foi determinado pelo número de afiliados, ou: quantos são, efetivamente, os afiliados em cada uma das organizações sindicais? Qual é o órgão que avalia a taxa de sindicalização? Por que isso é importante, se pensamos, por exemplo, em sindicato de categoria? Porque pode acontecer de, por efeito das divisões internas no sindicato, por exemplo, entre os sindicatos da CGIL, os da FIM e os da UIL, esses últimos possam assinar contratos nacionais, mesmo não tendo a maioria entre os afiliados ou entre as RSU. 
das partes na individuação do critério de cálculo do crescimento salarial em relação à inflação; a introdução de um tratamento econômico mínimo, que não é o salário-mínimo ${ }^{27}$, e de um tratamento econômico global (que inclui as formas de bem-estar empresarial). O texto fixou, pela primeira vez, a avaliação da representatividade empresarial para limitar as assinaturas de contratos coletivos "piratas" 28 por parte de associações patronais não representativas.

Outra questão, como já observado, é a das dificuldades na representação dos trabalhadores mais precarizados. Certamente, a estrutura sindical enfrenta uma série de desafios que incluem uma capacidade renovada de negociação e proteção, no contexto de um marco regulatório cada vez mais desfavorável aos trabalhadores em termos de direitos e segurança do emprego. O caso italiano, todavia, se insere plenamente nas tendências europeias, seja nos pontos fortes (setor público, trabalhadores migrantes, aposentados), seja nos aspectos de dificuldades (setor privado, novas formas de emprego), e apresenta, em geral, desempenho mais positivo pela melhor capacidade organizativa ${ }^{29}$. Ao mesmo tempo, o instrumento

27 Na Itália, ao contrário de outros países europeus, não há salário-mínimo definido por lei. Normalmente, isso é identificado como o salário-base previsto em cada CCNL. A resistência, por parte do sindicato, diante da possível introdução de tal medida, é um tema recorrente na ação sindical que vê no salário-mínimo um ataque à sua autonomia negocial e um risco que pode levar ao rebaixamento salarial. Sobre este assunto, ver Leonardi (2014).

28 A expressão indica a assinatura dos contratos coletivos por parte de organizações sindicais que, com frequência, existem no papel (sindicato de papel). Alguns desses são, por exemplo, os sindicatos autônomos. As empresas podem ter interesse em assinar esses diversos contratos porque podem prever uma redução dos custos e de uma série de direitos que podem ser regulamentados principalmente nos CCNL, rubricados pelas confederações com as principais associações de representação dos empregadores.

29 Vale dizer, o caso da Itália é semelhante ao dos outros países europeus, com relação à maior taxa de sindicalização em alguns setores e à menor capacidade de representação entre os trabalhadores de alguns setores privados, ou entre os trabalhadores que possuem contratos de trabalho flexível. Ao contrário, do ponto de vista organizativo, o sindicato italiano é igual aos sindicatos europeus: apresenta maior capacidade quanto à oferta de serviços aos próprios associados e aos trabalhadores em geral. Retomo neste caso, novamente, a tese segundo a qual, 
legislativo tem assumido um espaço muito grande, mais que no passado, quando as garantias e tutelas dependiam, principalmente, da regulação contratual. Isso é, certamente, resultado do êxito da ação sindical e, ao mesmo tempo, determina uma mudança de posicionamento dos trabalhadores e aposentados da área da contratação sindical pela tutela jurídica.

Para concluir, como afirmava Accornero (1992, p. 20), "a crise do movimento sindical italiano não é dramática, mas é profunda”. Os acontecimentos dos últimos anos mostram que essa crise, de alguma forma, continua, mas não a ponto de reduzir drasticamente o peso e a capacidade de negociação dos sindicatos.

\section{Davide Bubbico}

é pesquisador em sociologia econômica e do trabalho no Departamento de Ciências Econômicas e Estatísticas da Universidade de Salerno (Itália). Além do trabalho

312 no campo acadêmico, colabora com os metalúrgicos da Federazione Impiegati Operai Metallurgici (Federação Italiana dos Operários Metalúrgicos) Fiom-Cgil Nazionale. Seus campos de pesquisa, além do sindicato, referem-se à análise da organização do trabalho e das condições de trabalho no setor industrial, estudos do mercado de trabalho e do desenvolvimento socioeconômico ao nível territorial.

\section{Bibliografia}

ACCORNERO, Aris. 1992. La parabola del sindacato: ascesa e declino di una cultura. Bologna: Il Mulino.

BAGLIONI, Guido (org.). 1989. Le relazioni industriali in Italia negli anni '80. Roma: Lavoro.

BARCA, Fabrizio. 1999. Il capitalismo italiano: storia di un compromesso senza riforme. Roma: Donzelli.

mesmo que o número de afiliados entre os trabalhadores ativos não cresça muito, o sindicato cresce do ponto de vista da oferta de serviços; cresce, em outros termos, sua capacidade de responder a demandas de tipo "assistencial" provenientes dos trabalhadores, assim como dos aposentados e, em parte, dos desempregados. 
BECCHI COLLIDÀ, Ada; NEGRELLLI, Serafino. 1986. La transizione nell'industria e nelle relazioni industriali: l'auto e il caso Fiat. Milano: Franco Angeli.

BERNACIAK, Magdalena, GUMBRELL-MCCORMICK, Rebecca; HYMAN, Richard. 2014. European trade unionism: from crisis to renewal? Brussels: European Trade Union Institute, report n. 133.

BONAZZI, Giuseppe. 1993. La scoperta del modello giapponese nella sociologia occidentale. Stato e Mercato, v. 3, n. 39, pp. 437-466.

BRAGA, Adolfo; CARRIERI, Mimmo. 2007. Sindacato e delegati alla prova del lavoro che cambia. Roma: Donzelli.

BUBBICO, Davide. 2003. Due generazioni in fabbrica: il lavoro operaio alla Whirlpool di Napoli. Napoli: Dante \& Descartes.

CARRIERI, Mimmo. 1995. L'incerta rappresentanza. Bologna: Il Mulino.

CARRIERI, Mimmo; FELTRIN, Paolo. 2016. Al bivio: lavoro, sindacato e rappresentanza nell'Italia di oggi. Roma: Donzelli.

CIARINI, Andrea; DORIGATTI, Lisa. 2017. Tra cooperazione e conflitto: sindacati e organizzazioni autonome nella rappresentanza del lavoro parasubordinato e professional. Quaderni di Rassegna Sindacale, n. 1, pp. 127-148.

CONGIU, Massimo. 2004. Lavoro e sindacato nell'Est europeo: quattro realtà a confronto. Roma: Ediesse.

CORIAT, Benjamin. 1993. Penser à l'envers: travail et organisation dans l'entreprise japonaise. Paris: Christian Bourgeois.

DEL ROSSI, Maria Paola. 2012. Modelli organizzativi e politiche di affiliazione in Europa: il modello inglese. Agricoltura e Economia, n. 9-10, pp. 51-59.

DE NICOLA, Alberto; QUATTROCCHI, Biagio (orgs.). 2016. Sindacalismo sociale: lotte e invenzioni istituzionali in Europa. Roma: Derive e Approdi.

DOELLGAST, Virginia; LILLIE, Nathan; PULIGNANO, Valeria (orgs). 2018. Reconstructing solidarity: labour unions, precarious work, and the politics of institutional change in Europe. Oxford: Oxford University Press.

FAIOLI, Michele. 2017. Jobs APP gig-economy e sindacato. Rivista Giuridica del Lavoro, n. 2, pp. 291-305.

FELTRIN, Paolo. 2005. La sindacalizzazione in Italia (1986-2004): tendenze e dinamiche di lungo periodo. Roma: Lavoro.

2010. La sindacalizzazione nel 2010. In: MASCINI, Massimo (org.). Annuario del lavoro 2010. Roma: Il Diario del Lavoro, pp. 315-330.

2015. Il fenomeno sindacale nell'Italia contemporanea: declino politico e ascesa di mercato. Quaderni di Rassegna Sindacale, n. 4, pp. 173-218. 
FELTRIN, Paolo; MASET, Sergio. 2010. Come resistere al declino: l'opzione dei servizi nei sindacati. Quaderni di Rassegna Sindacale, n. 3, pp. 177-210.

FERNIE, Sue; METCALF David (eds.). 2004. Trade unions: resurgence or demise? London: Routledge.

FILIPPINI, Roberta. 1988. L'accordo della discordia. Milano: Franco Angeli.

FRANCHI, Maura. 1991. Giovani e relazioni industriali: $i$ nuovi assunti nell'industria in Emilia-Romagna. Roma: Ediesse.

FRANK, Louis. 1990. Il corporativismo e l'economia dell'Italia fascista. Torino: Bollati Boringhieri.

FUMAGALLI, Andrea. 2014. Per una metamorfosi della rappresentanza e del conflitto sociale. Disponível em: <https://bit.ly/2JY8a6Q >. Acesso em: 17 maio 2018.

HARRISON, Bennett. 1994. Lean and mean: the changing landscape of corporate power in the age of flexibility. New York: Basic Books.

INSTITUTO NAZIONALE DI STATISTICA. 2014. Struttura e occupazione delle imprese: registro statistico delle imprese attive (ASIA). Disponível em: <https:/ /bit.ly/2mJ8hdv>. Acesso em: 30 abr. 2018.

LIVIADOTTI, Stefano. 2008. L'altra casta: privilegi, carriere, misfatti e fatturati da multinazionale: l'inchiesta sul sindacato. Milano: Bompiani. LEONARDI, Salvo. 2005. Bilateralità e servizi: quale ruolo per il sindacato? Roma: Ediesse.

2014. Salario minimo e ruolo del sindacato: il quadro europeo fra legge e contrattazione. Lavoro e Diritto, v. 28, n. 1, pp. 185-211.

MAGDA, Iga. 2017. Do trade unions in Central and Eastern Europe make a difference? Bonn: Institute for the Study of Labor. Disponível em: $<$ https://bit.ly/2OkS4YA>. Acesso em: 10 maio 2018.

MANGHI, Bruno. 1977. Declinare crescendo: note critiche dall'interno del sindacato. Bologna: Il Mulino.

MINGIONE, Enzo et al. 2014. Le organizzazioni sociali e i giovani professionisti nell'area milanese. Quaderni di Rassegna Sindacale, n. 1, pp. 123-140.

MOTTURA, Giovanni; COZZI, Silvia; RINALDINI, Matteo. 2010. Uscire da babele: percorsi e problemi del rapporto tra sindacato e lavoratori immigrati. Roma: Ediesse.w

NEGT, Oskar. 1988. Lebendige Arbeit: enteignete Zeit: politische und kulturelle Dimensionen des Kampfes um die Arbeitszeit. Frankfurt am Main: Campus.

OLINI, Gabriele. 2016. I contratti nazionali: quanti sono e perché crescono. Giornale di Diritto del Lavoro e di Relazioni Industriali, n. 3, pp. $417-436$. 
PACI, Massino. 1982. Onde lunghe nello sviluppo dei sistemi di welfare. Stato e Mercato, n. 6, pp. 345-400.

PELLEGRINI, Claudio. 2015. Un'analisi dei dati Istat su contrattazione e sindacalizzazione. Disponível em: <https:/ / bit.ly/2LcvImJ >. Acesso em: 30 abr. 2018.

PIORE, Michael; SABEL, Charles. 1984. The second industrial divide: possibilities for prosperity. New York: Basic Books.

PIZZORNO, Alessandro. 1977. Scambio politico e identità collettiva nel conflitto industriale. In: CROOUCH, Colin; PIZZORNO, Alessandro (orgs.). Conflitti in Europa: lotte di classe, sindacati e Stato dopo il '68. Milano: Etas, pp. 407-433.

REBAUDENGO, Paolo. 2015. Nuove regole in fabbrica: dal contratto Fiat alle nuove relazioni industriali. Bologna: Il Mulino.

REGALIA, Ida. 2009. Quale rappresentanza: dinamiche e prospettive del sindacato in Italia. Roma: Ediesse.

REGINI, Marino. 2007. Associazione degli interessi, regolazione del lavoro e sviluppo economico. In: REGINI, Marino (org.). La sociologia economica contemporanea. Bari: Laterza, pp. 258-283.

ROMAGNOLI, Guido. 1976. Consigli di fabbrica e democrazia sindacale. Milano: Mazzotta.

SABATTINI, Claudio; POLO, Gabriele. 2000. Restaurazione italiana: Fiat, la sconfitta operaia dell'autunno 1980: alle origini della controrivoluzione liberista. Roma: Manifestolibri.

TURONE, Silvio. 1981. Storia del sindacato in Italia: 1943-1980. Bari: Laterza.

VALENTI, Alberto. 2014. Corsi e ricorsi della concertazione sociale in Italia. Lavoro e Diritto, n. 4, pp. 621-646. 


\section{O SINDICALISMO ITALIANO ENTRE CRISE DE REPRESENTATIVIDADE E MUDANÇAS DAS RELAÇÕES INDUSTRIAIS}

\section{DAVIDE BUBBICO}

Resumo: Desde o início dos anos 1980, o sindicalismo confederal italiano (CGIL, CISL, UIL) vive uma crise de representatividade que se explica pela redução da taxa de sindicalização e pela dificuldade de representar as novas formas de emprego produzidas pelos processos de reforma do mercado do trabalho nas últimas três décadas. As tentativas de superação dos contratos nacionais de categoria têm sido mais evidentes nos últimos anos, mas a mesma negociação no âmbito do segundo nível não tem ganhado mais espaço. Novas formas de organização na representação dos trabalhadores precários, fora da esfera do sindicato tradicional, e o maior dinamismo dos sindicatos de base extraconfederal na representação dos trabalhadores imigrantes são dois elementos que contribuem para crise atual. Isso não significa a perda da sua importância nas definições das normas regulatórias no campo das relações industriais com o Estado em matérias de interesse coletivo no mundo do trabalho (previdência, mercado do trabalho etc.).

Palavras-chave: Sindicato; Relações Industriais; Mercado do Trabalho; Negociação Coletiva.

\section{ITALIAN TRADE UNIONISIM BETWEEN CRISIS OF}

\section{REPRESENTATIVITY AND CHANGES IN INDUSTRIAL RELATIONS}

Abstract: Since the beginning of the 1980s, the Italian confederal unionism (CGIL, CISL, UIL) has been undergoing a crisis of representativity, explained by the reduction in the rate of unionization and the difficulty of representing the new forms of employment produced by labor market reform processes in the last 
three decades. At the same time, it managed to defend the existence of national collective labor agreements, even if the attempts to overcome national category contracts have been more evident in recent years, but the same second-level negotiation has not gained more space. New forms of organization in the representation of precarious workers, outside the scope of the traditional union, and the greater dynamism of extra-confederal unions in the representation of immigrant workers are two elements that contribute to this crisis today. However, this does not mean the loss of its importance in the definitions of the regulatory norms in industrial relations and with the State on matters of collective interest in the world of work (social welfare, labor market, etc.).

Keywords: Trade Union; Industrial Relations; Labor Market; Collective Bargaining.

Recebido: 04/06/2018 Aprovado: 22/07/2018 